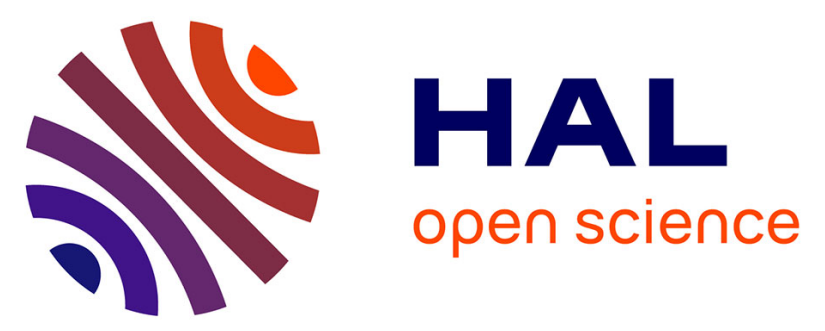

\title{
Using Torque-Angle and Torque- Velocity Models to Characterize Elbow Mechanical Function: Modeling and Applied Aspects
}

\author{
Diane Haering, Charles Pontonnier, Nicolas Bideau, Guillaume Nicolas, \\ Georges Dumont
}

\section{To cite this version:}

Diane Haering, Charles Pontonnier, Nicolas Bideau, Guillaume Nicolas, Georges Dumont. Using Torque-Angle and Torque- Velocity Models to Characterize Elbow Mechanical Function: Modeling and Applied Aspects. Journal of Biomechanical Engineering, 2019, 141 (8), pp.084501. 10.1115/1.4043447 . hal-02074561

\section{HAL Id: hal-02074561 \\ https://inria.hal.science/hal-02074561}

Submitted on 5 Apr 2019

HAL is a multi-disciplinary open access archive for the deposit and dissemination of scientific research documents, whether they are published or not. The documents may come from teaching and research institutions in France or abroad, or from public or private research centers.
L'archive ouverte pluridisciplinaire HAL, est destinée au dépôt et à la diffusion de documents scientifiques de niveau recherche, publiés ou non, émanant des établissements d'enseignement et de recherche français ou étrangers, des laboratoires publics ou privés. 


\title{
USING TORQUE-ANGLE AND TORQUE- VELOCITY MODELS TO CHARACTERIZE ELBOW MECHANICAL FUNCTION: MODELING AND APPLIED ASPECTS
}

\author{
Haering, Diane ${ }^{1}$ \\ IBHGC, ENSAM ParisTech, F-75014 Paris, France \\ diane.haering@gmail.com \\ Pontonnier, Charles \\ Univ Rennes, CNRS, INRIA, IRISA, UMR6074, F-35000 Rennes. \\ charles.pontonnier@ens-rennes.fr
}

Bideau, Nicolas

Univ Rennes, M2S, EA1274, F-35000 Rennes.

nicolas.bideau@univ-rennes2.fr

Nicolas, Guillaume

Univ Rennes, M2S, EA1274, F-35000 Rennes.

guillaume.nicolas@univ-rennes2.fr

Dumont, Georges

Univ Rennes, CNRS, INRIA, IRISA, UMR6074, F-35000 Rennes.

georges.dumont@ens-rennes.fr

\footnotetext{
${ }^{1}$ Corresponding author
} 
Journal of Biomechanical Engineering

\section{ABSTRACT}

Characterization of muscle mechanism through the torque-angle and torque-velocity relationships is critical for human movement evaluation and simulation. In-vivo determination of these relationships through dynamometric measurements and modelling is based on physiological and mathematical aspects. However, no investigation regarding the effects of the mathematical model and the physiological parameters underneath these models was found. The purpose of the current study was to compare the capacity of various torque-angle and torque-velocity models to fit experimental dynamometric measurement of the elbow and provide meaningful mechanical and physiological information. Therefore, varying mathematical function and physiological muscle parameters from the literature were tested. While a quadratic torqueangle model seemed to increase predicted to measured elbow torque fitting, a new power-based torquevelocity parametric model gave meaningful physiological values to interpret with similar fitting results to a classical torque-velocity model. This model is of interest to extract modeling and clinical knowledge characterizing the mechanical behavior of such a joint.

1 Keywords: maximal joint torque - isokinetic dynamometer - torque-angle-velocity 2 relationship, maximal power velocity, muscle mechanics. 


\section{INTRODUCTION}

Joint strength models are valuable representations of the torque generation

6 capacities of a human, useful in direct assessment as well as in musculoskeletal modeling

7 and analyses of human body. These models assume that muscles are viscoelastic

8 actuators [1-3], resulting at the joint level in Joint Torque-Angle and Torque-Velocity

9 Relationships (JTAR and JTVR respectively, and their coupling JTAVR). Fitting such models

10 to specific subjects while keeping their physiological meaning relevant remains an issue.

11 Basically, models are fitted to isokinetic measurements of joint torques in different angle

12 and angular velocity conditions [1-3].

13 At sarcomere scale, force-length relationship is asymmetrical piecewise linear due

14 to actin and myosin cross-bridge dynamics [4]. At muscle scale, the inter-fiber variability

15 blurs the transient states [5]. At joint scale, muscle-specific non-linear moment arms [6]

16 bring additional transformation into the torque-angle relationship. These observations

17 make it difficult to choose between various JTAR models, and no consensus exists in the

18 literature: normal curve [7,8], quadratic spline [9,10], cubic spline [11], cosinus wave [12],

19 or sinus exponential wave [13]. In a previous study, differences between those models in

20 fitting experimental isokinetic measures have been observed [14], particularly in the

21 eccentric portion of JTAR, evidencing the interaction between angle and velocity in such

22 models. Meanwhile, JTVR is mostly represented with hyperbolic functions $[15,16]$,

23 although it might not cover all the joint velocity range [17].

24 JTAR and JTVR integrate parameters supposed to be physiologically meaningful.

25 At joint scale, parameters reflect partially the muscle physiology, even if the joint reflects 
26 the interaction between multiple muscles. For JTAR, maximal isometric torque $\Gamma_{\max }$,

27 optimal isometric angle $\alpha_{0}$, and maximal range of motion RoM, are recurrent parameters.

28 For JTVR, Yeadon et al. 2006 [18] introduced maximal eccentric torque, maximal

29 concentric velocity and technical parameters. Anderson, et al. 2007 [12] added eccentric

30 to concentric force ratio and velocities at $75 \%$ and $50 \%$ of maximal isometric force within

31 the physiological range. In this last model, the two concentric parameters are dependent;

32 and the model lacks derivative continuity between concentric and eccentric portions that

33 can lead to unrealistic JTAVR fitting to data, particularly exhibiting continuity jumps. As

34 proposed in [19], maximal range of velocity can be useful for JTVR extrapolation in high

35 velocity regions.

36 Besides models fitting issues, physiological significance is useful for interpretation.

37 For example, maximal strength and muscle compositions are useful in ergonomics

$38[20,21]$. In sports, specific velocity at maximal power can be a training focus [22]. In clinics,

39 eccentric to concentric strength ratio is an indicator for pathology [23]. Last,

40 musculoskeletal analysis needs such parameters to calibrate models to subjects $[24,25]$.

41 A direct in-vivo estimation of these parameters remains an issue, since it requires

42 cadaveric, invasive or expensive measurements [24-27]. Joint strength models are

43 therefore useful to get these values indirectly $[12,24,28]$.

44 The purpose of the current study is to investigate the effects of mathematical

45 models and muscle parameters on JTAR and JTVR from modeling and applied points of

46 views. We assumed that:

47 - [H1] an asymmetrical JTAR can reduce torque prediction errors; 
- [H2] a new power-based JTVR can improve the physiological relevance of such models.

\section{METHODS}

\section{$51 \quad$ Ethics and Participants}

52 Under INRIA national ethics committee agreement (COERLE \#2017-002), twenty-two

53 male participants ( $33 \pm 6$ years; $1.81 \pm 0.07 \mathrm{~m} ; 78 \pm 9 \mathrm{~kg}$ ) gave their informed consent to

54 participate in the study.

\section{Isokinetic measurement}

56 Participants seated upright with the arm alongside on a Con-Trex $\mathrm{MJ}^{\circledR}$ isokinetic

57 dynamometer (CMV AG, Dübendorf, Switzerland) according the manual guidelines

58 (fig. 1). The dynamometer axis was aligned with the elbow flexion axis at $90^{\circ}$ for maximum

59 precision. Maximal distance between handle and arm brace without hampering elbow

60 flexion was chosen to minimize elbow displacement away from the dynamometer axis.

61 Similarly, tight straps were used to immobilize thorax. Range of motion was adjusted to

62 the subject.

63 Goniometric measurement was used to calibrate angular values. Three passive flexion-

64 extension trials at $60^{\circ} . \mathrm{s}^{-1}, 120^{\circ} . \mathrm{s}^{-1}$, or $180^{\circ} . \mathrm{s}^{-1}$ were recorded for gravity and passive 65 components compensation.

66 After a ten minutes sub-maximal warm-up, five voluntary flexion or extension hold for

67 five seconds at angles evenly spaced throughout the range of motion were recorded as 68 isometric trials. Then, three repetitions of concentric-passive cycles at $60^{\circ} . \mathrm{s}^{-1}, 120^{\circ} . \mathrm{s}^{-1}$, or $69180^{\circ} . \mathrm{s}^{-1}$ or eccentric-passive trials at $60^{\circ} . \mathrm{s}^{-1}, 120^{\circ} . \mathrm{s}^{-1}$, or $180^{\circ} . \mathrm{s}^{-1}$ in flexion and extension 
70 were recorded as isokinetic trials. Within subject ranges of motion, reaching isokinetic

71 state limited the maximal velocity to $180^{\circ} . \mathrm{s}^{-1}$. During $180^{\circ} . \mathrm{s}^{-1}$ trials, subjects were asked

72 to anticipate their effort at the end of the previous passive cycle to decrease delay and

73 ensure a sufficient maximal contraction time during trials. To decrease fatigue effects,

74 trials order was randomized within subjects, flexion and extension trials were alternated,

75 and a 45 seconds rest was respected between each trial. All measurements were collected

76 by the same experimenter. Angle, angular velocity and torque were recorded at $256 \mathrm{~Hz}$.

77 Only data corresponding to isokinetic states were used for analysis, discarding the first

78 milliseconds of trials ( $215 \mathrm{~ms}$ to $355 \mathrm{~ms}$ ) during which muscle activation is not maximal

79 [18]. For each condition, the repetition with the largest average torque was selected.

81 INSERT FIGURE 1 HERE

\section{JTAR models}

84 Five JTAR mostly encountered in the literature were implemented as Normal $[3,10]$,

85 Quadratic [11,12], Cosinus [13], Cubic [14] and Sinus-exponential [15] models.

86 Parameters of all these models are the maximal isometric torque $\Gamma_{\max }$, the optimal joint

87 angle $\alpha_{0}$ and the maximal range of isometric force production $R o M$. These models are

88 extensively described in the supplementary material and presented in figure 2.

89

90 INSERT FIGURE 2 HERE 


\section{JTVR models}

93 Two JTVR models were compared. The Anderson-based model is an adapted version of

94 [12]. The power-based model is a new polynomial function of the maximal power velocity

95 and other physiological parameters selected from the literature.

96 The Anderson-based model introduces 3 parameters: $\omega_{\boldsymbol{\Gamma}_{.75}}$ - Velocity at $75 \%$ of maximal

97 isometric torque , $E$ - Eccentric to concentric torque index and an additional $\omega_{\Gamma_{.5}} / \omega_{\Gamma_{.75}}$

98 ratio as an optimization constraint rather than an arbitrary value as in the original version.

99 The power-based model depends on the concentric velocity at maximal power, $\boldsymbol{\omega}_{\boldsymbol{P}_{\max }}$,

100 because of its unique correlation with muscle composition $[29,30] . \boldsymbol{\omega}_{\boldsymbol{P}_{\max }}$ is also used as

101 an inflexion constraint for the concentric part of the JTAR. The model also depends on

$102 \omega_{\min } / \omega_{\max }-$ Max. eccentric to concentric velocity ratio, $\Gamma_{E C C} / \Gamma_{C O N}-$ Max. eccentric to

103 concentric torque ratio and $\boldsymbol{\omega}_{\max }$ - Maximum concentric velocity at which muscle sustains

104 no more tension [31].

105 Both models are extensively described in the supplementary material and presented in

106 figure 3.

107

108 INSERT FIGURE 3 HERE

109

\section{Fitting models to data}

111 A least-square-curve-fitting method (trust-region algorithm, Matlab ${ }^{\circledast}$ Optimization

112 Toolbox ${ }^{\mathrm{TM}}$ ) minimized the quadratic distance between modelled and measured torques

113 by optimizing models parameters. 
114 Isometric, concentric and eccentric parameters were optimized in successive steps as

115 recommended by [12]. The five JTAR models were tested in the isometric step and were

116 combined with both JTVR models in the $2^{\text {nd }}$ and $3^{\text {rd }}$ steps.

117 Since range of motion and acquisition rate were constant for all trial, duration and frame

118 number varied for each velocity. To guarantee equal weight of all velocities on fitting,

119 samples of equal number of frames were selected within the algorithm.

\section{Models comparison}

121 First, models were compared in terms of ability to fit data. Adjusted correlation and linear

122 regression coefficients were compared between all combinations of JTAR and JTVR

123 models. Additionally, a one-way repeated measures Anova was performed to test the

124 effects of JTAR models on isometric torque prediction errors; and a two-way repeated

125 measures Anova was performed to test the effects of JTAR and JTVR models on isokinetic

126 (concentric + eccentric) torque prediction errors. Mauchly normality and sphericity test

127 was performed. Then, the Distribution Cumulative Differences (Matlab ${ }^{\circledR}$ Statistics \&

128 Machine Learning Toolbox ${ }^{\mathrm{TM}}$ ) was performed for the Anovas. Results are presented with

129 significance level set to $p \leq .05$ and significance power $\mathrm{F}$.

130 Second, the optimized parameters of all models were compared and confronted to 131 literature values.

\section{RESULTS}

133 The significant effects of JTAR and JTVR were not different between flexion or extension

134 motions. Results for both motions are presented together in this section. 
135 Torque predicted by cosinus, quadratic, and cubic models displayed larger correlation

136 with experimental data than normal and sinus-exponential models (table 1). Highest

137 correlations were obtained for isometric data. Correlation for concentric data was higher

138 with the power-based model than with the Anderson-based model but lower for eccentric 139 data.

141 INSERT TABLE 1 HERE

143 Sphericity was verified for all data $(p<0.01)$. ANOVA revealed that JTAR had significant

144 effects on isometric prediction errors $(p<0.01, F=3.86)$. Post-hoc tests attributed the 145 smallest errors to the quadratic model ( $p<0.001$, Fig 4a). Error increased significantly of

$1460.19,0.53,2.67$, and $4.25 \mathrm{~N} . \mathrm{m}$ between cosinus, cubic, sinus-exponential and normal 147 models respectively.

148 The ANOVA showed an ordinal interaction between these models on average error $(p<$ $1490.01, F=18.36)$, plus significant effects of JTAR $(p<0.01, F=13.15)$ and JTVR $(p<$ $1500.05, F=4.66)$. Normal and sinus-exponential models still displayed the largest errors 151 10\% larger than other models - in combination with both JTVR models (Fig. 4b). The 152 power-based model displayed larger overall error than Anderson's model only when 153 combined with sinus-exponential and normal torque-angle models. 
157 Average isometric parameters obtained with each model are presented in table 2 . In

158 flexion, $\Gamma_{\max }$ varied between 63 N.m and 69 N.m, RoM varied between $155^{\circ}$ and $175^{\circ}$, and

$159 \alpha_{0}$ varied between $59^{\circ}$ and $102^{\circ}$. In extension, $\Gamma_{\max }$ between 60 N.m and 66 N.m, RoM

160 between $164^{\circ}$ and $179^{\circ}$, and $\alpha_{0}$ between $56^{\circ}$ and $99^{\circ}$ were obtained in extension.

161 Significant effects of the model were found for $\Gamma_{\max }$ and $\alpha_{0}$ only in extension $(p<0.05$,

$162 F=2.93$, and $p<0.01, F=3.90$ respectively). Average $\Gamma_{\max }$ obtained with cubic and

163 sinus-exponential models, and average $\alpha_{0}$ obtained with the normal model, differed by

164 more than $10 \%$ from values found in the literature.

INSERT TABLE 2 HERE

168 Optimal $\omega_{\max }, \omega_{\min }$, and $\omega_{P_{\max }}$ obtained from the new model combined to each isometric 169 model are presented in table 3. No statistical effect of the model was found for these 170 parameters.

172 INSERT TABLE 3 HERE

173

174 Optimal $\Gamma_{E C C} / \Gamma_{C O N}$ ratios obtained with both JTVR are presented in table 4 . The ANOVA 175 showed an effect of the JTAR, but no effect of the JTVR and an interaction between JTAR 176 and JTVR. Differences identified through the post-hoc tests were about $1 \%$ of the average 177 ratio values. 
INSERT TABLE 4 HERE

\section{Discussion}

182 The purpose of the current study was to investigate the capacity of JTAR and JTVR models

183 to represent the elbow mechanical function from modeling and applied points of views.

184 We first compared their ability to fit the experimental data and then interpreted their

185 physiological parameters in comparison to the literature.

186 Differences in fitting experimental data were observed. Both choices of JTAR and JTVR

187 showed statistical effects and interaction on maximal torque prediction. For JTAR, [H1]

188 was not verified, since the asymmetrical models displayed significantly larger errors than

189 two of the symmetrical models (quadratic and cosinus). This may be explained by

190 interactions between maximal forces and moment arms of multiple muscles crossing the

191 elbow [6]. For the elbow joint, the quadratic JTAR appears as the most accurate and

192 adaptable model on a large cohort. Those results might be joint-specific. As reported in

193 our preliminary study [14], average prediction error is increased by the JTVR. Associated

194 with one of the two best JTAR (i.e. quadratic, cosinus, cubic), the power-based and

195 Anderson-based models gave similar prediction levels. Although the new physiological

196 parameters may improve the model meaningfulness, it did not improve its compliance to

197 fit measured data. Especially, the additional constraint added to ensure derivative

198 continuity between concentric and eccentric parts of the model seemed to decrease

199 eccentric fitting efficiency of the model. However, it ensured that the torque envelope

200 generated by the fitting method was continuous, that may not be the case with the 
201 Anderson-based one. Globally, correlations between measured and predicted JTAVR

202 were weaker in the current study than in other studies in the literature that focused on

203 lower limbs [14,21]. This result may be due to the larger anatomical variability of the

204 upper limb. Moreover, larger misalignment between elbow and dynamometer axes may

205 arise during motion because of the equipment, since the arm position cannot be as

206 controlled as the thigh on the dynamometer. Quantification and correction of this

207 problem could improve the fitting quality and the subsequent parameter estimation.

208 Specific joint strengths models dedicated to fitting may also have been of interest to be

209 tested here $[5,36]$

210

211 For applied perspectives, physiological parameters obtained through optimization of the

212 models seem coherent with the literature. For a group of young healthy men, maximal

213 isometric torque $\Gamma_{\max }$ between $63 \mathrm{~N} . \mathrm{m}$ and $69 \mathrm{~N} . \mathrm{m}$ in flexion [2,32], and balanced flexion-

214 extension ratios between .95 and .97 are similar to literature [2,33]. Range of motion RoM

215 obtained with all models is larger than the anatomical reference [34], probably due to an

216 extrapolation of muscle strength beyond realistic elbow configuration due to bony limits.

217 Average optimal angle, $\alpha_{0}$, obtained for elbow flexion and extension with all models are

218 consistent with the literature [35-37]. For both flexion and extension, $\alpha_{0}$ found for normal

$219\left(79^{\circ}, 76^{\circ}\right)$, cosinus $\left(77^{\circ}, 72^{\circ}\right)$, and quadratic $\left(77^{\circ}, 72^{\circ}\right)$ models was close to classically

220 observed average angles $[38,39]$, while cubic $\left(59^{\circ}, 56^{\circ}\right)$ and sinus-exponential $\left(112^{\circ}, 99^{\circ}\right)$

221 models values were at boundaries. Only $\Gamma_{\max }$ obtained with cubic and sinus-exponential 
222 models, and $\alpha_{0}$ obtained with the normal model differed by more than $10 \%$ from

223 literature values $[32,38]$.

224 Concerning concentric and eccentric parameters, concentric velocity at maximal power,

$225 \omega_{P_{\max }}$, was our focus. Due to its relationship with muscle composition [30], linking

226 mechanical and physiological muscle functions, the implementation of this parameter in

227 the model seemed interesting for applications in sports, rehabilitation or ergonomics [40].

228 Optimized $\omega_{P_{\max }}$ values, between $404^{\circ} . \mathrm{s}^{-1}$, and $561^{\circ} . \mathrm{s}^{-1}$, are about two times larger than

$229 \omega_{P_{\max }}$ values only based on isokinetic dynamometer for thigh muscles [29]. Previous study

230 showed that measured $\omega_{P_{\max }}$ correlated better $(r=.55)$ with fiber composition when

231 corrected with a Hill-type model as in our study [41] and could have values between

$232215^{\circ} . \mathrm{s}^{-1}$ and $539^{\circ} . \mathrm{s}^{-1}$. Although correlations are seen, only $51.8 \%$ of the fiber composition

233 variance was explained by $\omega_{P_{\max }}$ [42]. For further work, a combination of $\omega_{P_{\max }}$

234 measurements with Hill-model correction and electromyography could be investigated

235 [43] and a validation of muscle composition prediction through this technique should be 236 performed.

237 For the other concentric and eccentric parameters, maximal concentric velocity, $\omega_{\max }$, 238 between $1268^{\circ} . \mathrm{s}^{-1}$ and $1531^{\circ} . \mathrm{s}^{-1}$ in flexion and, $1368^{\circ} . \mathrm{s}^{-1}$ and $1667^{\circ} . \mathrm{s}^{-1}$ in extension were 239 found. That lays below values reported for baseball players, middle-aged, and elderly men 240 respectively $[43,44]$. The normal and sinus-exponential models produced the smallest 241 values. For maximal eccentric velocity, $\omega_{\min }$, no conclusive reference data were found. In 242 general, physiological parameters related to velocity were obtained by extrapolation of 243 our model beyond highest velocity measured in this study. Since no direct measurement 
244 for much higher velocities was possible with such dynamometers, these values cannot be

245 directly validated.

246 Since the degree of meaningfulness of the power-based JTVR was higher, without

247 decreasing significantly the data fitting, [H2] seemed verified.

249 To conclude, five JTAR and two JTVR were compared when fitting experimental 250 dynamometric measurements from modelling and applied perspectives. While a 251 quadratic torque-angle model fitted best the data, a new proposed JTVR increased

252 physiological transparency and clinical relevance without decreasing significantly the data

253 fitting. The study highlights the needs for improvement of dynamometric measurement

254 accuracy for the upper limb and the importance of the meaningfulness of the 255 physiological parameters to be optimized when fitting these models to data.

\section{AKNOWLEDGMENT}

The authors want to acknowledge INRIA who funded a post-doctoral scholarship on this

260 project.

261

262 CONFLICT OF INTEREST

263

264 The authors encountered no conflict of interest for the current study. 


\section{REFERENCES}

[1] Bosco, C., Belli, A., Astrua, M., Tihanyi, J., Pozzo, R., Kellis, S., Tsarpela, O., Foti, C., Manno, R., and Tranquilli, C., 1995, "A Dynamometer for Evaluation of Dynamic Muscle Work," Eur. J. Appl. Physiol., 70(5), pp. 379-386.

[2] Frey-Law, L. A., Laake, A., Avin, K. G., Heitsman, J., Marler, T., and Abdel-Malek, K., 2012, "Knee and Elbow 3D Strength Surfaces: Peak Torque-Angle-Velocity Relationships," J. Appl. Biomech., 28(6), pp. 726-737.

[3] Gülch, R. W., 2008, "Force-Velocity Relations in Human Skeletal Muscle," Int J Sports Med, 15(S 1), pp. S2-S10.

[4] Cole, G. K., Van Den Bogert, A. J., Herzog, W., and Gerritsen, K. G., 1996, "Modelling of Force Production in Skeletal Muscle Undergoing Stretch," J. Biomech., 29(8), pp. 1091-1104.

[5] Rassier, D., MacIntosh, B., and Herzog, W., 1999, "Length Dependence of Active Force Production in Skeletal Muscle," J. Appl. Physiol., 86(5), pp. 1445-1457.

[6] Murray, W. M., Delp, S. L., and Buchanan, T. S., 1995, "Variation of Muscle Moment Arms with Elbow and Forearm Position," J. Biomech., 28(5), pp. 513517-515525.

[7] Brown, I. E., Cheng, E. J., and Loeb, G. E., 1999, "Measured and Modeled Properties of Mammalian Skeletal Muscle. II. The Effects of Stimulus Frequency on ForceLength and Force-Velocity Relationships," J. Muscle Res. Cell Motil., 20(7), pp. 627643.

[8] Zajac, F. E., 1989, “Muscle and Tendon: Properties, Models, Scaling, and Application to Biomechanics and Motor Control," Crit. Rev. Biomed. Eng., 17(4), pp. 359-411.

[9] Chow, J. W., Darling, W. G., Hay, J. G., and Andrews, J. G., 1999, "Determining the Force-Length-Velocity Relations of the Quadriceps Muscles: III. A Pilot Study," J. Appl. Biomech., 15(2), pp. 200-209.

[10] van den Bogert, A. J., Gerritsen, K. G., and Cole, G. K., 1998, "Human Muscle Modelling from a User's Perspective," J. Electromyogr. Kinesiol. Off. J. Int. Soc. Electrophysiol. Kinesiol., 8(2), pp. 119-124.

[11] Lloyd, D. G., and Besier, T. F., 2003, "An EMG-Driven Musculoskeletal Model to Estimate Muscle Forces and Knee Joint Moments in Vivo," J. Biomech., 36(6), pp. 765-776.

[12] Anderson, D. E., Madigan, M. L., and Nussbaum, M. A., 2007, “Maximum Voluntary Joint Torque as a Function of Joint Angle and Angular Velocity: Model Development and Application to the Lower Limb," J. Biomech., 40(14), pp. 3105-3113.

[13] Hatze, H., 1977, “A Myocybernetic Control Model of Skeletal Muscle," Biol. Cybern., 25(2), pp. 103-119.

[14] Haering, D., Pontonnier, C., and Dumont, G., 2017, "Which Mathematical Model Best Fit the Maximal Isometric Torque-Angle Relationship of the Elbow?," Comput. Methods Biomech. Biomed. Engin., 20(sup1), pp. 101-102.

[15] Brown, I. E., Scott, S. H., and Loeb, G. E., 1996, "Mechanics of Feline Soleus: II. Design and Validation of a Mathematical Model," J. Muscle Res. Cell Motil., 17(2), pp. 221-233. 
[16] van Soest, A. J., Huijing, P. A., and Solomonow, M., 1995, "The Effect of Tendon on Muscle Force in Dynamic Isometric Contractions: A Simulation Study," J. Biomech., 28(7), pp. 801-807.

[17] Wickiewicz, T. L., Roy, R. R., Powell, P. L., Perrine, J. J., and Edgerton, V. R., 1984, "Muscle Architecture and Force-Velocity Relationships in Humans," J. Appl. Physiol., 57(2), pp. 435-443.

[18] Yeadon, M. R., King, M. A., and Wilson, C., 2006, "Modelling the Maximum Voluntary Joint Torque/Angular Velocity Relationship in Human Movement," J. Biomech., 39(3), pp. 476-482.

[19] Forrester, S. E., Yeadon, M. R., King, M. A., and Pain, M. T., 2011, “Comparing Different Approaches for Determining Joint Torque Parameters from Isovelocity Dynamometer Measurements," J. Biomech., 44(5), pp. 955-961.

[20] Haering, D., Pontonnier, C., Bideau, N., Nicolas, G., and Dumont, G., 2017, "Task Specific Maximal Elbow Torque Model For Ergonomic Evaluation," Proceedings of the XXVI Congress of the International Society of Biomechanics.

[21] Moore, J. S., and Garg, A., 1995, "The Strain Index: A Proposed Method to Analyze Jobs for Risk of Distal Upper Extremity Disorders," Am. Ind. Hyg. Assoc. J., 56(5), pp. 443-458.

[22] Haff, G. G., and Nimphius, S., 2012, "Training Principles for Power," Strength Cond. J., 34(6).

[23] Hedlund, M., Lindström, B., Sojka, P., Lundström, R., and Olsson, C.-J., 2017, "Pronounced Decrease in Concentric Strength Following Stroke Due to PreFrontally Mediated Motor Inhibition," Physiotherapy, 101, pp. e553-e554.

[24] Muller, A., Haering, D., Pontonnier, C., and Dumont, G., 2017, "Non-Invasive Techniques for Musculoskeletal Model Calibration," Congrès Français de Mécanique, Lille.

[25] Staron, R. S., Hagerman, F. C., Hikida, R. S., Murray, T. F., Hostler, D. P., Crill, M. T., Ragg, K. E., and Toma, K., 2000, "Fiber Type Composition of the Vastus Lateralis Muscle of Young Men and Women," J. Histochem. Cytochem. Off. J. Histochem. Soc., 48(5), pp. 623-629.

[26] Sopher, R. S., Amis, A. A., Davies, D. C., and Jeffers, J. R., 2017, "The Influence of Muscle Pennation Angle and Cross-Sectional Area on Contact Forces in the Ankle Joint," J. Strain Anal. Eng. Des., 52(1), pp. 12-23.

[27] Veeger, H. E., Yu, B., An, K. N., and Rozendal, R. H., 1997, "Parameters for Modeling the Upper Extremity," J. Biomech., 30(6), pp. 647-652.

[28] Croisier, J. L., and Crielaard, J. M., 1999, "Exploration Isocinétique: Analyse Des Paramètres Chiffrés," Ann. Réadapt. Médecine Phys., 42(9), pp. 538-545.

[29] Froese, E. A., and Houston, M. E., 1985, "Torque-Velocity Characteristics and Muscle Fiber Type in Human Vastus Lateralis," J. Appl. Physiol., 59(2), pp. 309-314.

[30] Schantz, P., Randal Fox, E., Hutchison, W., Tydén, A., and Åstrand, P., 1983, "Muscle Fibre Type Distribution, Muscle Cross-sectional Area and Maximal Voluntary Strength in Humans," Acta Physiol., 117(2), pp. 219-226.

[31] Hill, A. V., 1938, "The Heat of Shortening and the Dynamic Constants of Muscle," Proc. R. Soc. Lond. B Biol. Sci., 126(843), pp. 136-195. 
[32] Gauthier, A., Davenne, D., Martin, A., and Van Hoecke, J., 2001, “Time of Day Effects on Isometric and Isokinetic Torque Developed during Elbow Flexion in Humans," Eur. J. Appl. Physiol., 84(3), pp. 249-252.

[33] Ellenbecker, T. S., and Roetert, E. P., 2003, "Isokinetic Profile of Elbow Flexion and Extension Strength in Elite Junior Tennis Players," J. Orthop. Sports Phys. Ther., 33(2), pp. 79-84.

[34] Boone, D. C., and Azen, S. P., 1979, "Normal Range of Motion of Joints in Male Subjects.," JBJS, 61(5), pp. 756-759.

[35] Chang, Y.-W., Su, F.-C., Wu, H.-W., and An, K.-N., 1999, "Optimum Length of Muscle Contraction," Clin. Biomech., 14(8), pp. 537-542.

[36] Koo, T. K. ., Mak, A. F. ., and Hung, L. ., 2002, "In Vivo Determination of SubjectSpecific Musculotendon Parameters: Applications to the Prime Elbow Flexors in Normal and Hemiparetic Subjects," Clin. Biomech., 17(5), pp. 390-399.

[37] Mountjoy, K., Morin, E., and Hashtrudi-Zaad, K., 2010, "Use of the Fast Orthogonal Search Method to Estimate Optimal Joint Angle for Upper Limb Hill-Muscle Models," IEEE Trans. Biomed. Eng., 57(4), pp. 790-798.

[38] Hasan, Z., and Enoka, R., 1985, "Isometric Torque-Angle Relationship and Movement-Related Activity," Exp Brain Res, 59, pp. 441-450.

[39] Thomis, M. A., Van Leemputte, M., Maes, H. H., Blimkie, C. J. R., Claessens, A. L., Marchal, G., Willems, E., Vlietinck, R. F., and Beunen, G. P., 1997, "Multivariate Genetic Analysis of Maximal Isometric Muscle Force at Different Elbow Angles," J. Appl. Physiol., 82(3), p. 959.

[40] Karp, J. R., 2001, "Muscle Fiber Types and Training.," Strength Cond. J., 23(5), p. 21.

[41] MacIntosh, B. R., Herzog, W., Suter, E., Wiley, J. P., and Sokolosky, J., 1993, "Human Skeletal Muscle Fibre Types and Force: Velocity Properties," Eur. J. Appl. Physiol., 67(6), pp. 499-506.

[42] Suter, E., Herzog, W., Sokolosky, J., Wiley, J. P., and Macintosh, B. R., 1993, "Muscle Fiber Type Distribution as Estimated by Cybex Testing and by Muscle Biopsy.," Med. Sci. Sports Exerc., 25(3), pp. 363-370.

[43] Kim, C., Gao, Q., Kim, W., and Kim, W., 1994, "Muscle Fiber Type Distribution Estimated by Non-Invasive Technique: Based on Isometric Force and Integrated Electromyography," Clin. Sci., 87(s1), p. 107.

[44] Toji, H., and Kaneko, M., 2007, "Effects of Aging on Force, Velocity, and Power in the Elbow Flexors of Males," J. Physiol. Anthropol., 26(6), pp. 587-592. 


\section{Figure Captions List}

Fig. 1 Experimental set up. The participant is seated and attached to the ConTrex dynamometer in upright position with the arm along his side. The axis of the dynamometer is aligned with the epicondylitis axis with the elbow flexed at $90^{\circ}$.

Fig. 2 Normalized torque-angle relationship as defined by the five mathematical models: normal, cosinus, and quadratic models are symmetrical; cubic and sinus-exponential are asymmetrical.

Fig. 3 Normalized torque-velocity models and constraint parameters: in the Anderson-based model (A), we find one derivative constraint at $\omega_{\max }$, two independent constraints at $-\omega_{\max }$ and $\omega_{0}$, and two dependant constraints at $\boldsymbol{\omega}_{\Gamma_{.5}}$ and $\boldsymbol{\omega}_{\Gamma_{.75}}$; in our power-based model $(\mathrm{B})$, we defined three derivative constraints and three independent constraints at $\omega_{\max }, \omega_{\max }$, and $\omega_{0}$, and an additional derivative constraints at $\omega_{P_{\max }}$ on the powervelocity relationship.

Fig. 4 Effects of torque-angle models $(A)$ and interaction between the torqueangle and torque-velocity models (B) on average prediction errors. Colored stars represent individuals (one color = one subject). Black dots, blue dots and red diamonds represent the average of all individuals. Asterisks indicate significant difference between means.

390 
Table 1 Adjusted correlation coefficients between measured and predicted maximal torque for all models in elbow flexion and extension for each type of data: isometric, concentric and eccentric.

Table 2 Optimal elbow torque-angle parameters obtained with the five isometric models.

Table 3 Optimal elbow torque-velocity parameters of the new model obtained with the five isometric models.

Table 4 Optimal elbow eccentric to concentric ratios obtained with Andersonbased model and the new model combined with each of the five isometric models. 
Figure 1-Experimental set up. The participant is seated and attached to the ConTrex

396 dynamometer in upright position with the arm along his side. The axis of the

397 dynamometer is aligned with the epicondylitis axis with the elbow flexed at $90^{\circ}$.

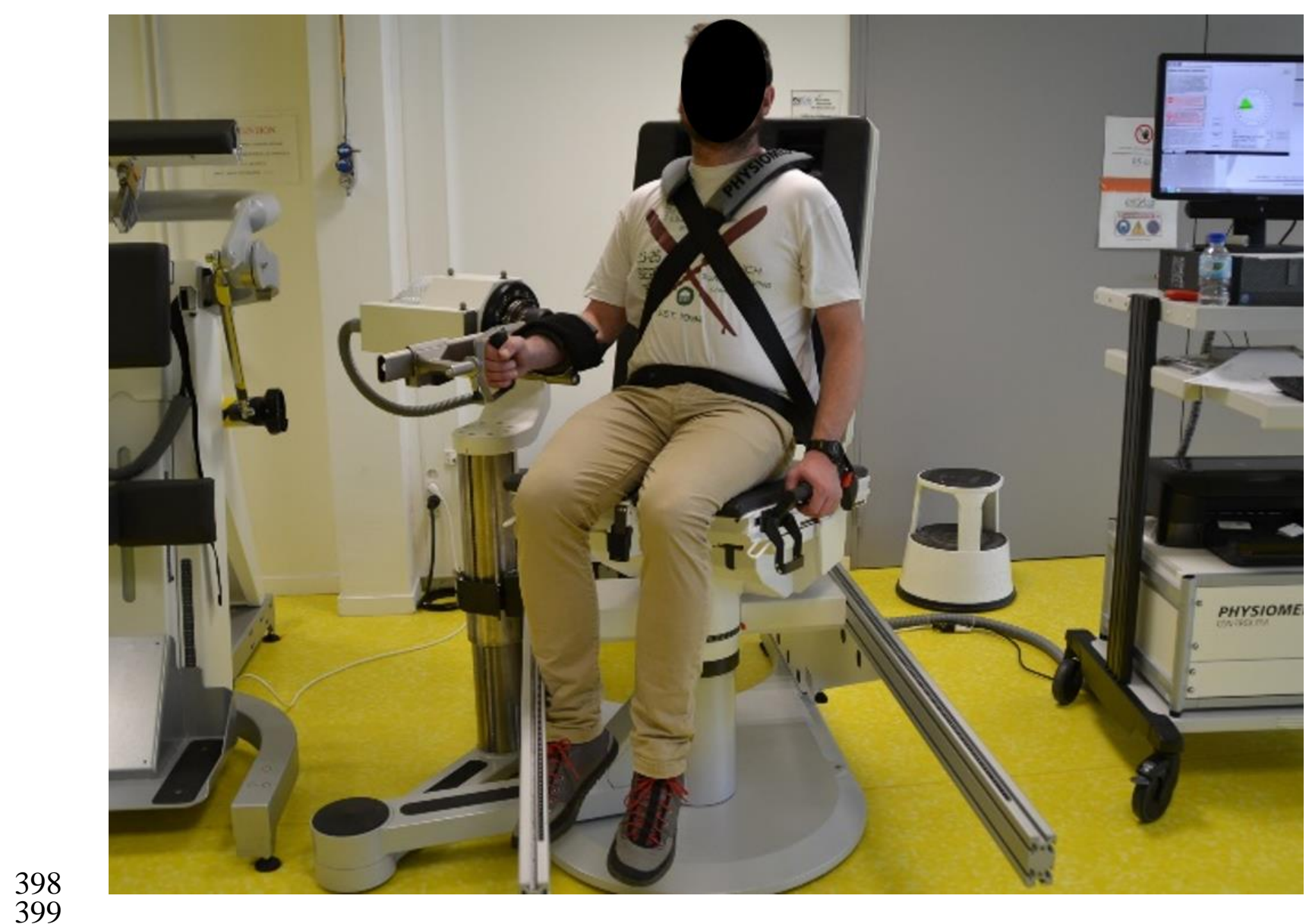


400 Figure 2 - Normalized torque-angle relationship as defined by the five mathematical 401 models: normal, cosinus, and quadratic models are symmetrical; cubic and sinus402 exponential are asymmetrical.

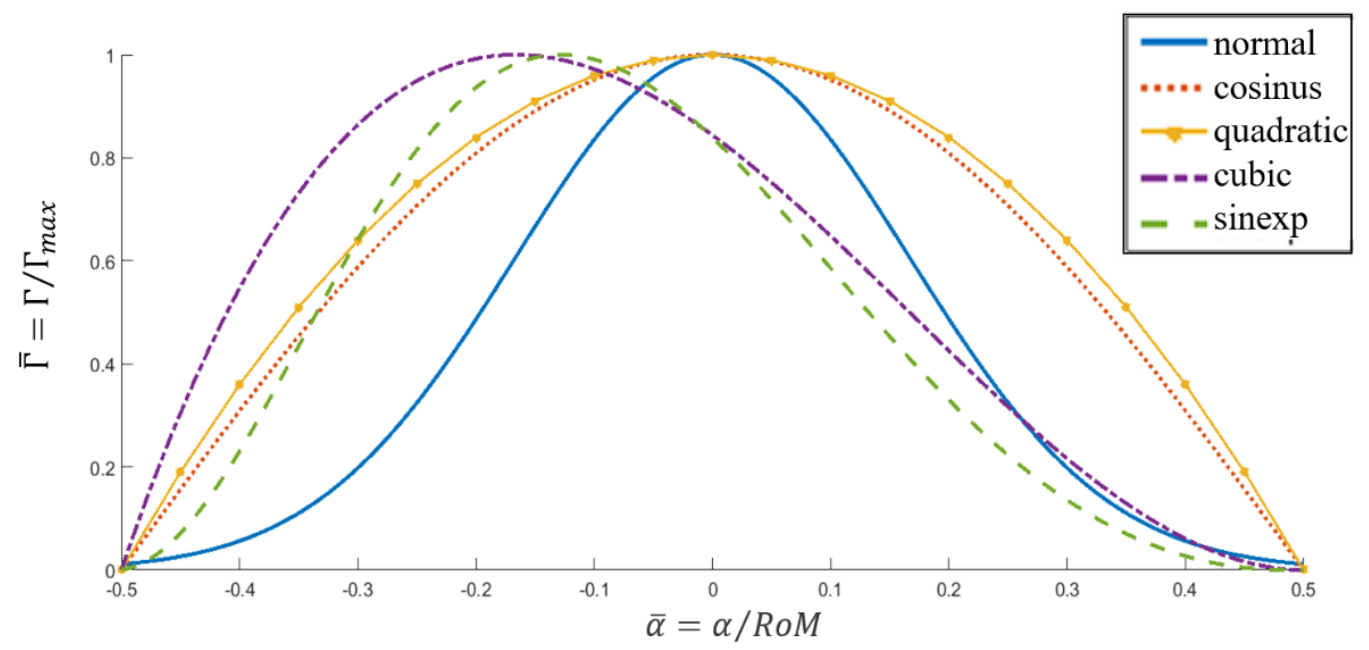


405 Figure 3 - Normalized torque-velocity models and constraint parameters: in the 406 Anderson-based model (A), we find one derivative constraint at $\omega_{\max }$, two independent

407 constraints at $-\omega_{\max }$ and $\omega_{0}$, and two dependant constraints at $\omega_{\Gamma_{.5}}$ and $\omega_{\Gamma_{.75}}$; in our

408 power-based model (B), we defined three derivative constraints and three independent

409 constraints at $\omega_{\max }, \omega_{\max }$, and $\omega_{0}$, and an additional derivative constraints at $\omega_{P_{\max }}$ on

410 the power-velocity relationship.
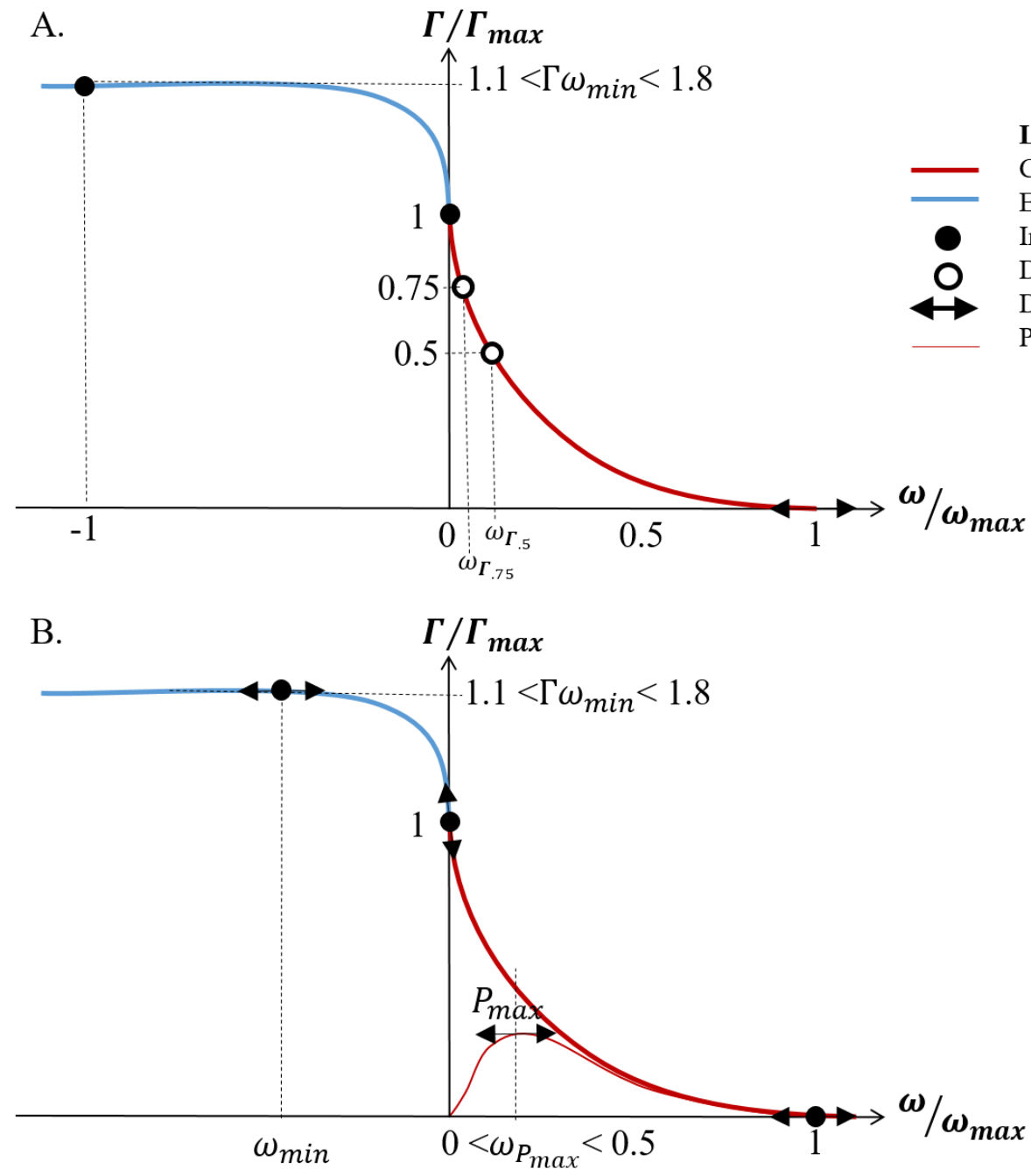
412 Figure 4 - Effects of torque-angle models (A) and interaction between the torque-angle

413 and torque-velocity models (B) on mean errors computed as the average difference

414 between maximal torque measured on the dynamometer and maximal torque predicted

415 by the models. Colored stars represent individuals (one color = one subject). Black dots,

416 blue dots and red diamonds represent the average of all individuals. Asterisks indicate

417 significant difference between means.

418

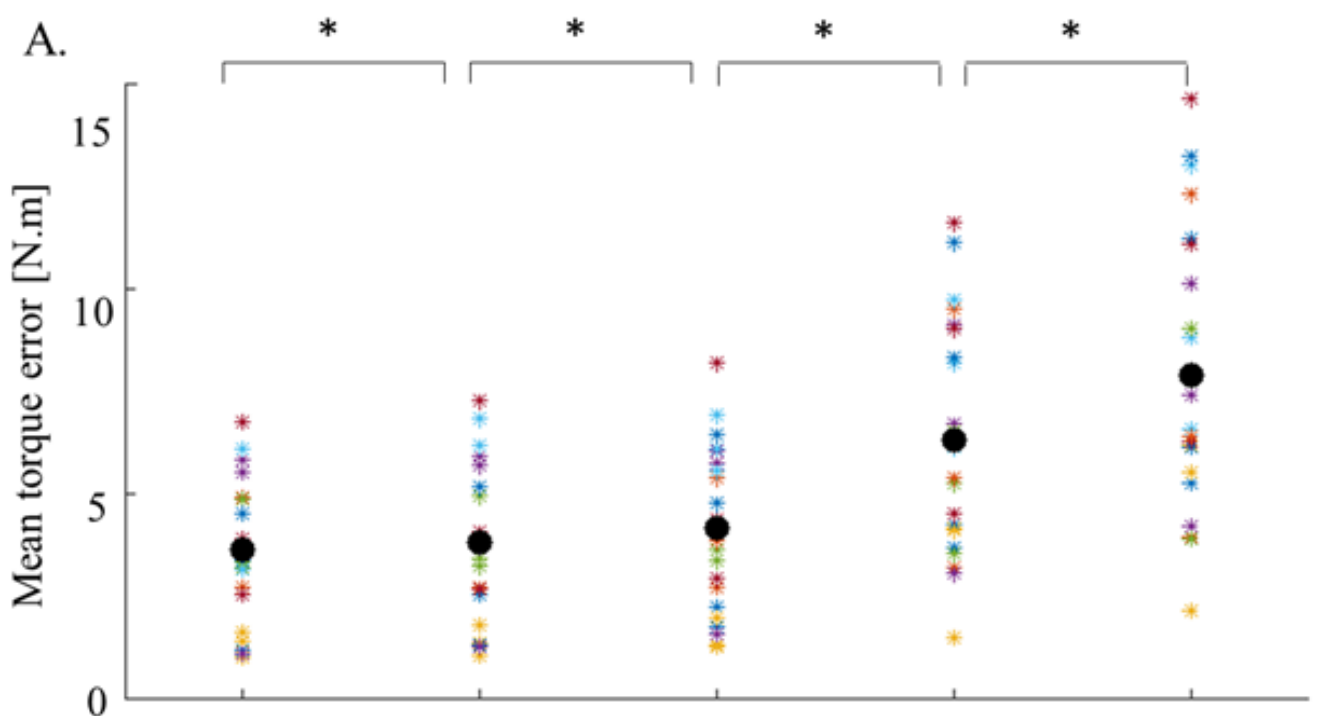

B.

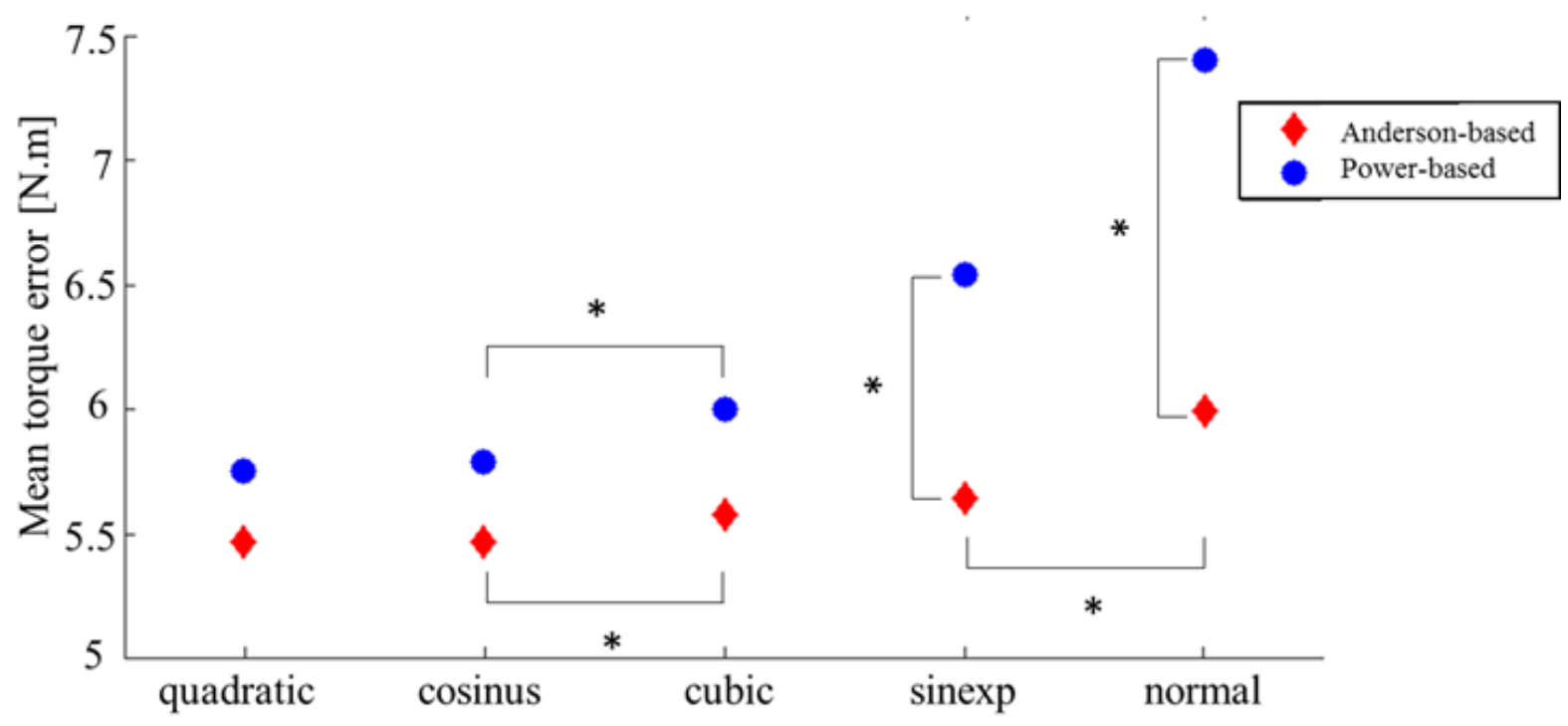


421 Table 1. Adjusted correlation coefficients between measured and predicted maximal

422 torque for all models in elbow flexion and extension for each type of data: isometric,

423 concentric and eccentric.

\begin{tabular}{|c|c|c|c|c|c|c|c|}
\hline \multicolumn{3}{|l|}{$\mathbf{R}^{2}$} & 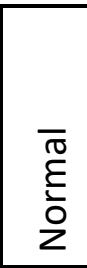 & : & 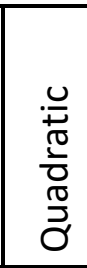 & $\frac{0}{3}$ & 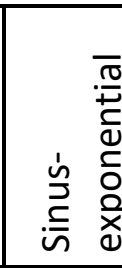 \\
\hline \multirow{6}{*}{$\begin{array}{l}\text { Anderson } \\
\text {-based } \\
\text { model }\end{array}$} & \multirow[t]{3}{*}{ flexion } & Isometric & \multirow{3}{*}{$\begin{array}{l}.62 \\
.58 \\
.75\end{array}$} & \multirow{3}{*}{$\begin{array}{l}.86 \\
.62 \\
.75\end{array}$} & \multirow{3}{*}{$\begin{array}{l}.87 \\
.62 \\
.75 \\
\end{array}$} & \multirow{3}{*}{$\begin{array}{l}.84 \\
.61 \\
.74\end{array}$} & \multirow{3}{*}{$\begin{array}{l}.74 \\
.61 \\
.77 \\
\end{array}$} \\
\hline & & Concentric & & & & & \\
\hline & & Eccentric & & & & & \\
\hline & \multirow[t]{3}{*}{ extension } & Isometric & \multirow{3}{*}{$\begin{array}{l}.66 \\
.74 \\
.71\end{array}$} & \multirow{3}{*}{$\begin{array}{l}.88 \\
.75 \\
.77\end{array}$} & \multirow{3}{*}{$\begin{array}{l}.89 \\
.75 \\
.77 \\
\end{array}$} & \multirow{3}{*}{$\begin{array}{l}.87 \\
.76 \\
.76\end{array}$} & \multirow{3}{*}{$\begin{array}{l}.75 \\
.74 \\
.74 \\
\end{array}$} \\
\hline & & Concentric & & & & & \\
\hline & & Eccentric & & & & & \\
\hline \multirow{6}{*}{$\begin{array}{l}\text { Power- } \\
\text { based } \\
\text { model }\end{array}$} & \multirow[t]{3}{*}{ flexion } & Isometric & \multirow{3}{*}{$\begin{array}{l}.62 \\
.64 \\
.60\end{array}$} & \multirow{3}{*}{$\begin{array}{l}.86 \\
.70 \\
.64\end{array}$} & \multirow{3}{*}{$\begin{array}{l}.87 \\
.70 \\
.64\end{array}$} & \multirow{3}{*}{$\begin{array}{l}.84 \\
.68 \\
.62\end{array}$} & \multirow{3}{*}{$\begin{array}{l}.74 \\
.68 \\
.64\end{array}$} \\
\hline & & Concentric & & & & & \\
\hline & & Eccentric & & & & & \\
\hline & \multirow[t]{3}{*}{ extension } & Isometric & \multirow{3}{*}{$\begin{array}{l}.66 \\
.81 \\
.64\end{array}$} & \multirow{3}{*}{$\begin{array}{l}.88 \\
.85 \\
.70\end{array}$} & \multirow{3}{*}{$\begin{array}{l}.89 \\
.85 \\
.70\end{array}$} & \multirow{3}{*}{$\begin{array}{l}.87 \\
.85 \\
.70\end{array}$} & \multirow{3}{*}{$\begin{array}{l}.75 \\
.82 \\
.67\end{array}$} \\
\hline & & Concentric & & & & & \\
\hline & & Eccentric & & & & & \\
\hline
\end{tabular}

424 
425 Table 2. Optimal elbow torque-angle parameters obtained with the five isometric models.

426 Values displayed in the table correspond to: means \pm standard deviations.

\begin{tabular}{|c|c|c|c|c|c|c|c|c|c|c|c|c|c|c|c|}
\hline & & Norr & & & Cosi & & Qua & rat & & Cub & & & Sin $u$ & ex & \\
\hline \multirow{3}{*}{$\begin{array}{l}z \\
\frac{0}{x} \\
\text { ü }\end{array}$} & $\Gamma_{\max }[\mathrm{N} . \mathrm{m}]$ & & \pm & 13 & & \pm 11 & & \pm & 11 & & \pm & 11 & 66 & \pm & 12 \\
\hline & $\operatorname{RoM}\left[{ }^{\circ}\right]$ & 175 & \pm & 17 & 160 & \pm 33 & 155 & \pm & 34 & 167 & \pm & 28 & 173 & \pm & 24 \\
\hline & $\alpha_{0} \quad\left[{ }^{\circ}\right]$ & 79 & \pm & 10 & & \pm 13 & 77 & \pm & 14 & 102 & \pm & 12 & 59 & \pm & 10 \\
\hline \multirow{3}{*}{$\begin{array}{l}z \\
\text { o } \\
\text { n } \\
\dot{w} \\
\underset{\mathbf{x}}{x}\end{array}$} & $\Gamma_{\max }[$ N.m] & 66 & \pm & 18 & 60 & \pm 16 & 60 & \pm & 16 & 61 & \pm & 17 & 64 & \pm & 18 \\
\hline & $\operatorname{RoM}\left[{ }^{\circ}\right]$ & 179 & \pm & 4 & 167 & \pm 27 & 164 & \pm & 30 & 169 & \pm & 23 & 173 & \pm & 20 \\
\hline & $\begin{array}{ll}\alpha_{0} & \left.{ }^{\circ}\right]\end{array}$ & 76 & \pm & 9 & 72 & \pm 11 & 72 & \pm & 11 & 99 & \pm & 10 & 56 & \pm & 9 \\
\hline
\end{tabular}


429 Table 3. Optimal elbow torque-velocity parameters of the new model obtained with the

430 five isometric models. Values displayed in the table correspond to: means \pm standard

431 deviations.

\begin{tabular}{|c|c|c|c|c|c|c|c|c|c|c|}
\hline \multicolumn{2}{|c|}{ Torque-angle model } & \multicolumn{2}{|c|}{ Normal } & Cosinus & \multicolumn{2}{|c|}{ Quadratic } & \multicolumn{2}{|l|}{ Cubic } & \multicolumn{2}{|c|}{ Sinus-exp } \\
\hline \multirow{3}{*}{$\begin{array}{l}z \\
\text { 으 } \\
\text { 出 } \\
\text { u }\end{array}$} & $\boldsymbol{\omega}_{\max }\left[{ }^{\circ} \cdot \mathrm{s}^{-1}\right]$ & $1268 \pm$ & 514 & $1517 \pm 544$ & $1531 \pm$ & 548 & $1492 \pm$ & 567 & $1331 \pm$ & 507 \\
\hline & $\omega_{\min }\left[{ }^{\circ} \cdot \mathrm{s}^{-1}\right]$ & $-173 \pm$ & 87 & $-301 \pm 276$ & $-369 \pm$ & 500 & $-330 \pm$ & 477 & $-238 \pm$ & 241 \\
\hline & $\boldsymbol{\omega}_{P_{\max }}\left[{ }^{\circ} \cdot \mathrm{S}^{-1}\right]$ & $404 \pm$ & 231 & $495 \pm 242$ & $502 \pm$ & 500 & $490 \pm$ & 255 & $426 \pm$ & 225 \\
\hline \multirow{3}{*}{ 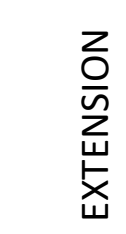 } & $\boldsymbol{\omega}_{\max }\left[{ }^{\circ} \cdot \mathrm{s}^{-1}\right]$ & $1368 \pm$ & 647 & $1636 \pm 747$ & $1667 \pm$ & 754 & $1605 \pm$ & 738 & $1458 \pm$ & 683 \\
\hline & $\omega_{\min }\left[{ }^{\circ} \cdot \mathrm{s}^{-1}\right]$ & $-297 \pm$ & 329 & $-509 \pm 464$ & $-531 \pm$ & 482 & $-536 \pm$ & 530 & $-391 \pm$ & 410 \\
\hline & $\boldsymbol{\omega}_{P_{\max }}\left[{ }^{\circ} \cdot \mathrm{S}^{-1}\right]$ & $432 \pm$ & 291 & $551 \pm 343$ & $563 \pm$ & 347 & $537 \pm$ & 337 & $473 \pm$ & 305 \\
\hline
\end{tabular}

432

433 
434 Table 4. Optimal elbow eccentric to concentric ratios obtained with Anderson-based

435 model and the new model combined with each of the five isometric models. Values

436 displayed in the table correspond to: means \pm standard deviations.

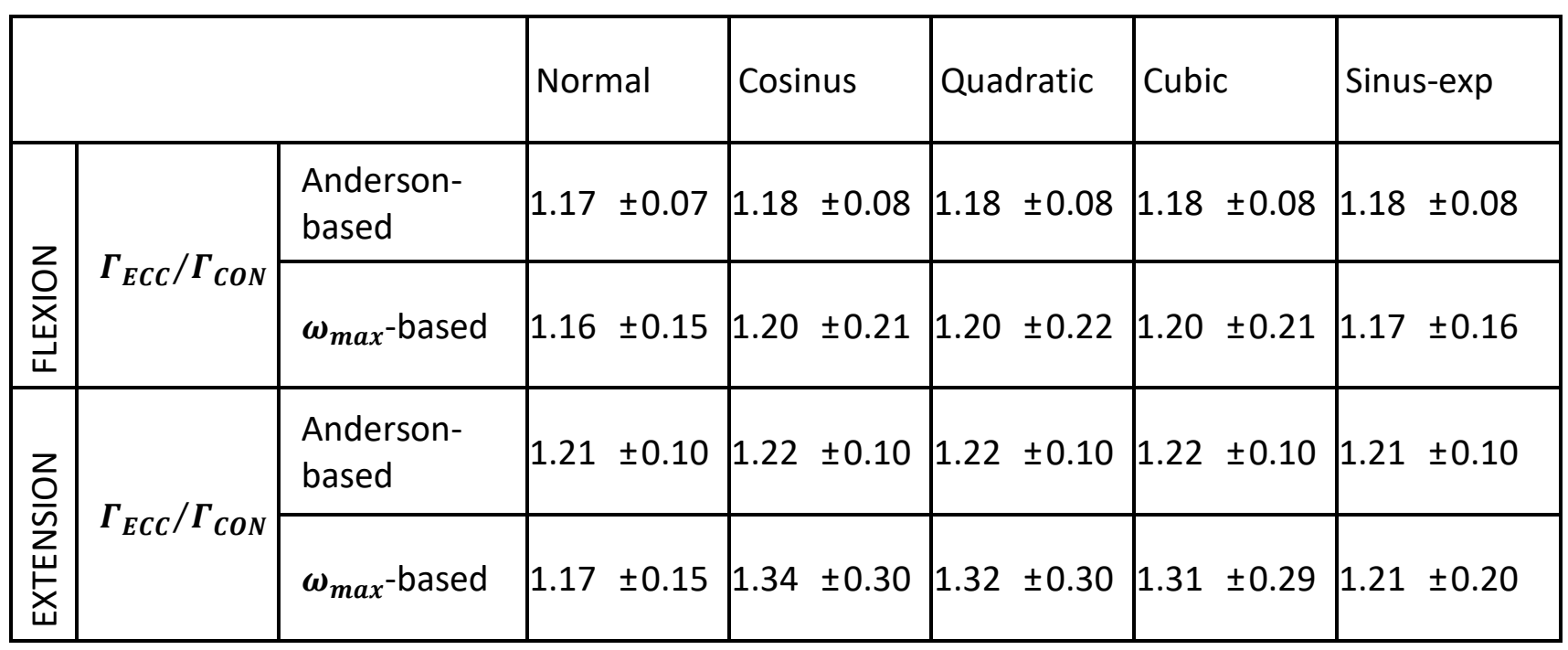


SUPPLEMENTARY MATERIAL

\section{USING TORQUE-ANGLE AND TORQUE-VELOCITY MODELS TO CHARACTERIZE ELBOW MECHANICAL FUNCTION: MODELING AND APPLIED ASPECTS}

Diane Haering, Charles Pontonnier, Nicolas Bideau, Guillaume Nicolas, Georges Dumont submitted to Journal of Biomechanical Engineering.

For the purpose of concision, the mathematical models used in the paper are extensively presented here.

\section{Joint Torque Angle Relationships (JTAR)}

$$
\begin{aligned}
& \text { Normal [8] } \\
& \Gamma(\bar{\alpha})=e^{-\frac{1}{2}(6 \bar{\alpha})^{2}} \\
& \text { Cosinus [12] } \\
& \Gamma(\bar{\alpha})=\cos (\pi \bar{\alpha}) \\
& \text { Quadratic }[9,15] \\
& \Gamma(\bar{\alpha})=-4 \bar{\alpha}^{2}+1 \\
& \text { Cubic [11] } \\
& \Gamma(\bar{\alpha})=\frac{27}{4} \bar{\alpha}^{3}-\frac{27}{8} \bar{\alpha}^{2}-\frac{27}{16} \bar{\alpha}+\frac{27}{32} \\
& \Gamma(\bar{\alpha})=\frac{1}{2} \sin \left(1.919 \pi e^{\bar{\alpha}}\right)+\frac{1}{2}
\end{aligned}
$$

452 In all of these models, the normalized maximal torque $\left(\overline{\boldsymbol{\Gamma}}=\frac{\boldsymbol{\Gamma}}{\Gamma_{\max }}\right)$ depended on the maximal

453 isometric torque and on the joint angle to optimal joint angle distance normalized by the maximal 454 range of isometric force production $\left(\overline{\boldsymbol{\alpha}}=\frac{\boldsymbol{\alpha}-\boldsymbol{\alpha}_{0}}{\boldsymbol{R o M}}\right)$ as presented in table 1. Those models are shown 455 in figure 1. All coefficients used for the normal, quadratic, cubic and sinus-exponential models 456 were obtained by solving the system of equations expressing the following constraints:

$\bar{\Gamma}\left(\bar{\alpha}_{0}\right)=1$,

$\bar{\Gamma}\left(\bar{\alpha}_{\text {min }}\right)=0$,

$\bar{\Gamma}\left(\bar{\alpha}_{\max }\right)=0$, and 


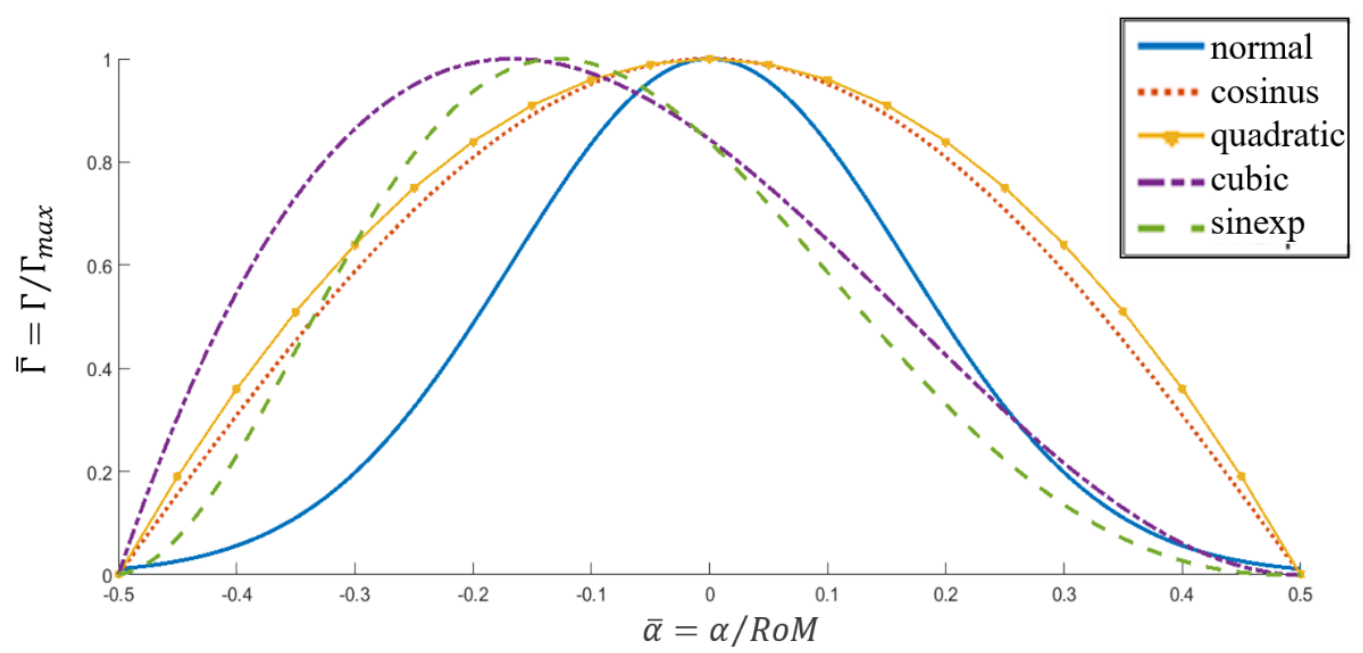

463 Figure 1 - Normalized torque-angle relationship as defined by the five mathematical

464 models: normal, cosinus, and quadratic models are symmetrical; cubic and sinus-

465 exponential are asymmetrical.

466

467 Table 1: JTAR parameters

\begin{tabular}{|c|c|c|c|}
\hline \multicolumn{2}{|c|}{ Parameters } & Limits & $\begin{array}{l}469 \\
470\end{array}$ \\
\hline$\Gamma_{\max }$ & Max. isometric torque & $0.75 \Gamma_{\text {meas }}$ & $\begin{array}{c}471 \\
1.25 \sqrt{7 m 2 n} \\
473\end{array}$ \\
\hline RoM & Max. isometric range of motion & 0 & $\begin{array}{l}474 \\
475 \\
476\end{array}$ \\
\hline$\alpha_{0}$ & Isometric optimal angle & $\pi / 6$ & $\begin{array}{r}5 \pi 4 \varnothing 7 \\
478\end{array}$ \\
\hline
\end{tabular}




\section{Table 2. JTVR parameters}

\begin{tabular}{|c|c|c|c|c|c|}
\hline Model & Par & ameters & & Limits & \\
\hline \multirow{3}{*}{$\begin{array}{l}\text { Anderson-based } \\
\text { torque-velocity } \\
\text { model }\end{array}$} & $P_{1}$ & $\omega_{\Gamma_{.75}}$ & Velocity at $75 \%$ of maximal isometric torque & 0 & $\pi$ \\
\hline & $P_{2}$ & $\omega_{\Gamma_{.5}} / \omega_{\Gamma_{.75}}$ & $\begin{array}{l}\text { Ratio between velocities at } 50 \% \text { and } 75 \% \text { of } \\
\text { maximal isometric torque }\end{array}$ & 1.9 & 2.1 \\
\hline & $P_{3}$ & $E$ & Eccentric to concentric torque index & .1 & .8 \\
\hline \multirow{4}{*}{$\begin{array}{l}\text { Power-based torque- } \\
\text { velocity model }\end{array}$} & $P_{1}$ & $\omega_{\max }$ & Max. concentric velocity & $\pi / 3$ & $5 \pi$ \\
\hline & $P_{2}$ & $\omega_{\boldsymbol{P}_{\max }}$ & Velocity at maximal power & 0.25 & 0.4 \\
\hline & $P_{3}$ & $\omega_{\min } / \omega_{\max }$ & Max. eccentric to concentric velocity ratio & -1 & -0.1 \\
\hline & $P_{4}$ & $\Gamma_{E C C} / \Gamma_{C O N}$ & Max. eccentric to concentric torque ratio & 1.1 & 1.8 \\
\hline
\end{tabular}

\subsection{Anderson-based model} torque index. 


\subsection{Power-based torque-velocity model}

$$
\left\{\begin{array}{c}
\Gamma(\bar{\omega})=0, \quad \mathbf{1} \leq \overline{\boldsymbol{\omega}} \\
\Gamma(\bar{\omega})=a_{1} \bar{\omega}^{3}+b_{1} \bar{\omega}^{2}+c_{1} \bar{\omega}+d_{1}, \quad \mathbf{0} \leq \overline{\boldsymbol{\omega}}<\mathbf{1} \\
\Gamma(\bar{\omega})=a_{2} \bar{\omega}^{3}+b_{2} \bar{\omega}^{2}+c_{2} \bar{\omega}+d_{2}, \boldsymbol{P}_{3} \leq \overline{\boldsymbol{\omega}}<\mathbf{0} \\
\Gamma(\bar{\omega})=P_{4}, \overline{\boldsymbol{\omega}}<\boldsymbol{P}_{3}
\end{array}\right.
$$

498 with:

with:

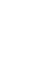




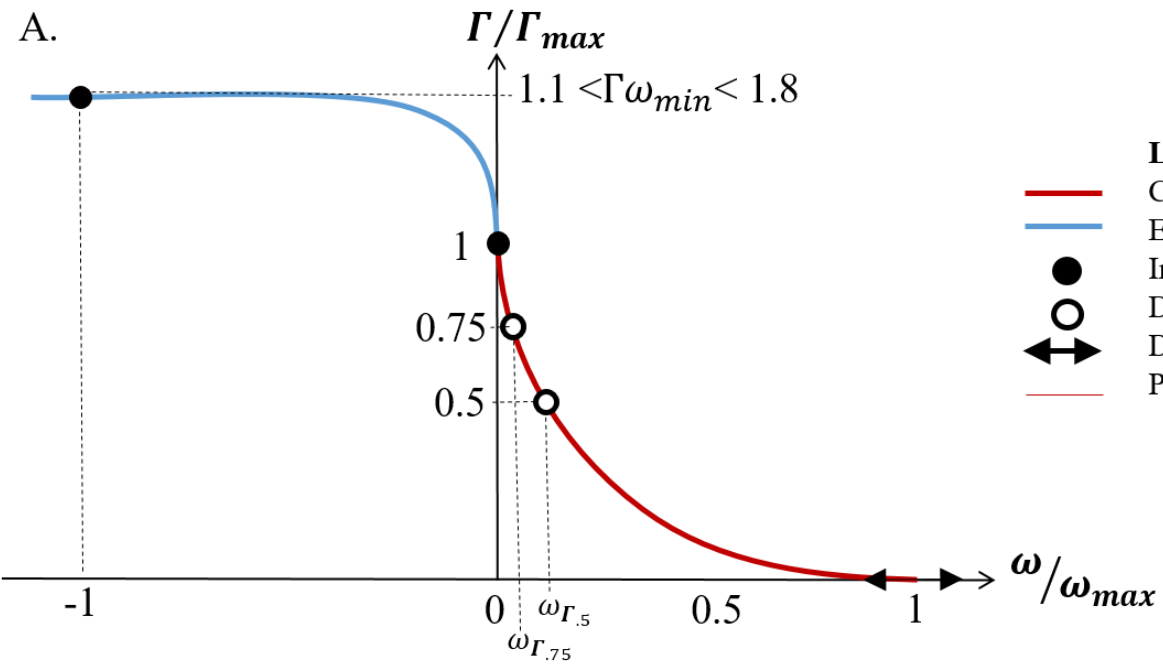

\section{Legend}

Concentric torque-velocity

Eccentric torque-velocity Independant point constraint Dependant point constraint

Derivative constraint

Power-velocity

B.

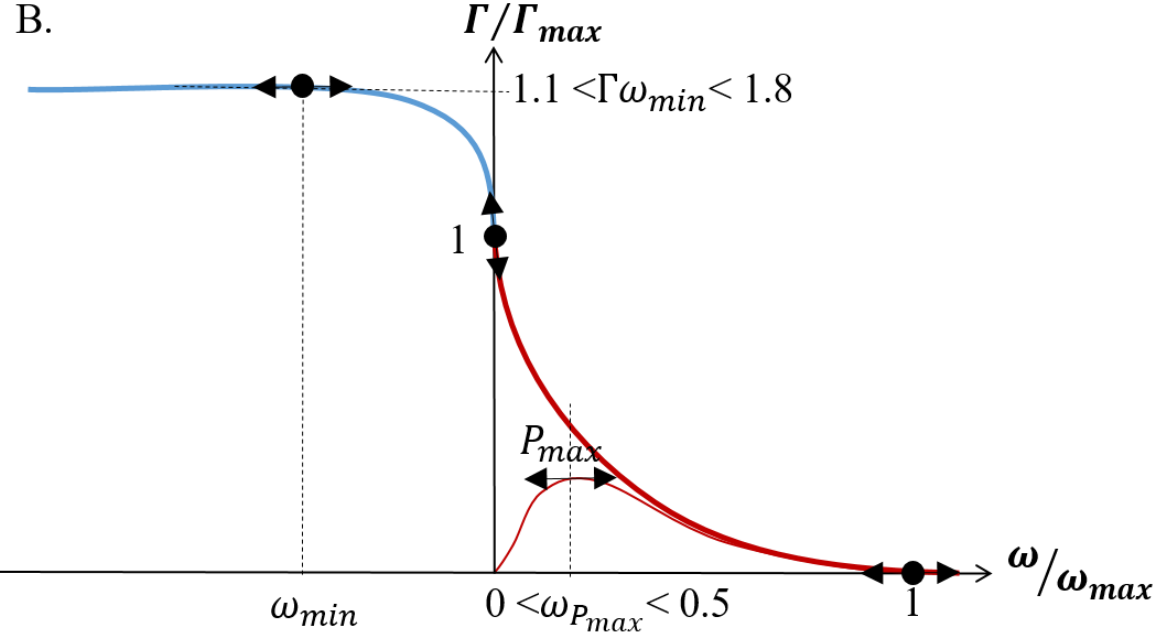

519 Figure 2 - Normalized torque-velocity models and constraint parameters: in the Anderson-based

520 model (A), we find one derivative constraint at $\omega_{\max }$, two independent constraints at $-\omega_{\max }$ and

$521 \omega_{0}$, and two dependant constraints at $\omega_{\Gamma_{.5}}$ and $\omega_{\Gamma_{.75}}$; in the power-based model (B), we defined

522 three derivative constraints and three independent constraints at $\omega_{\max }, \omega_{\max }$, and $\omega_{0}$, and an

523 additional derivative constraints at $\omega_{P_{\max }}$ on the power-velocity relationship. 


\section{Visualization of model to measurement fitting}

\subsection{Joint Torque Angle Relationships}

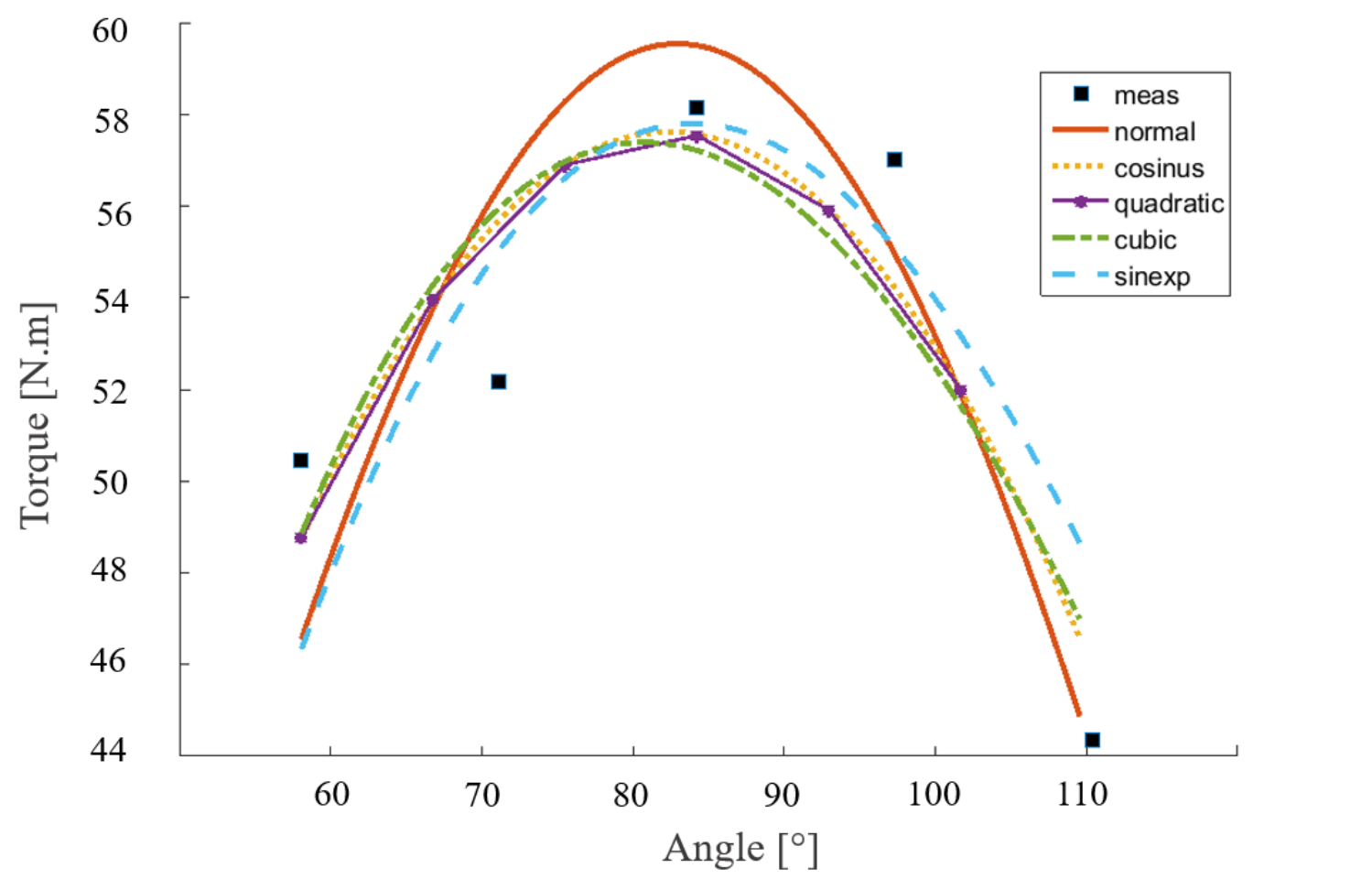

Figure 3 - Example of comparison between normal, cosines, quadratic, cubic and sinus 


\subsection{Joint Torque Angle \& Joint Torque Velocity Relationships}

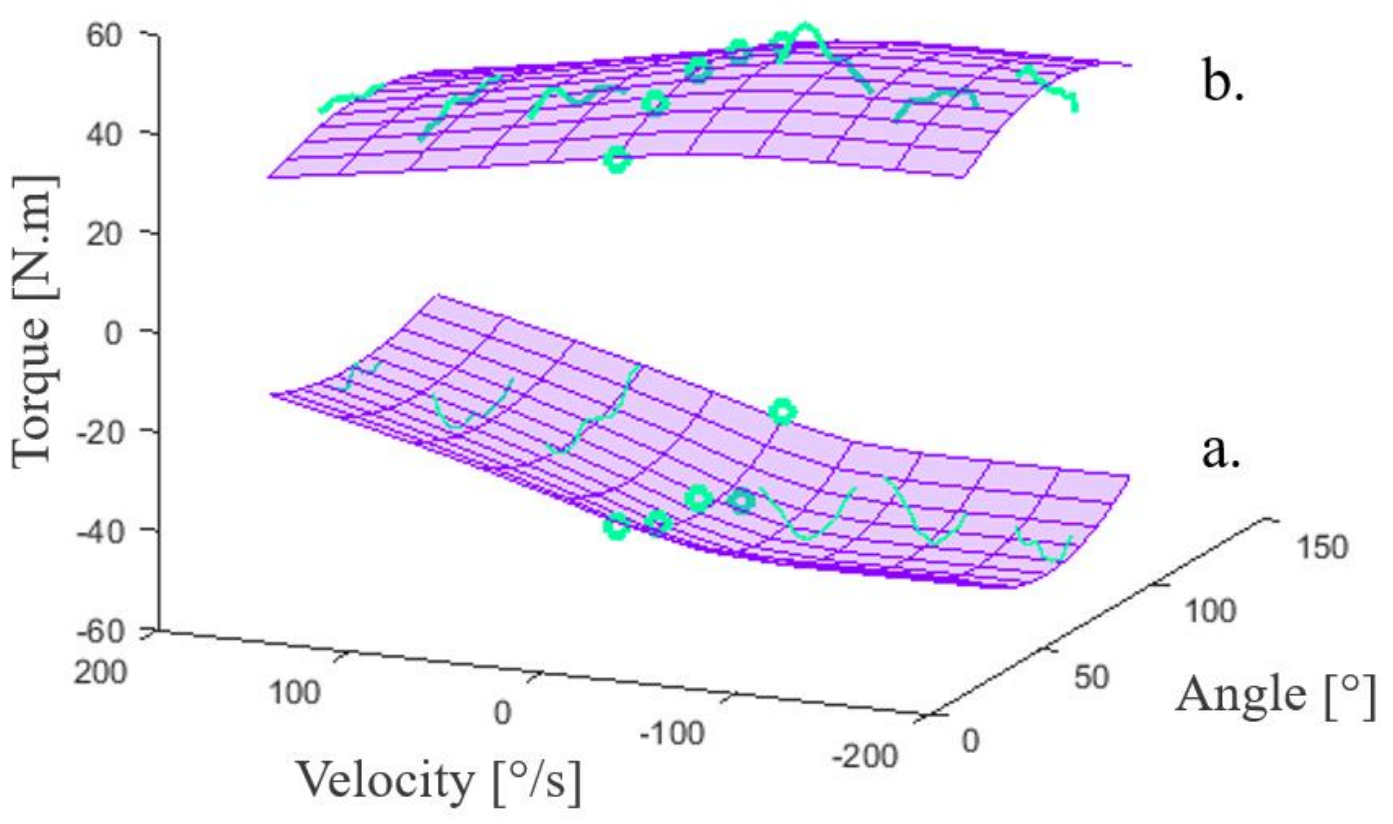

Figure 4 - Example of a combined JTAR and JTVR model mesh fitting on isometric maximum (dots) and isokinetic (lines) torque measurements for a. elbow flexion, and b. elbow extension. 